\title{
An Empirical Study on the Influence of Post-Merger Integration for Organizational Effectiveness: Focused on the Merged Corporation of LH
}

\author{
Hyo-Gon Moon', Eui-Joong Lee $^{2}$ and Yong-Tai $\mathrm{Kim}^{3}$ \\ (Received September 2, 2011 / Revised September 26, 2011 / Accepted October 19, 2011)
}

\begin{abstract}
In the merged organization, the efforts of integration such as various PMI activities, etc. are exerted and the performance of PMI can be judged by evaluating the effectiveness of an organization. In this paper, the empirical analysis was conducted to see what effects of 'planned PMI activities' and 'voluntary integration efforts' have on the effectiveness of an organization which is 'Organizational Commitment', 'Job Satisfaction', 'Emotional Integration' and 'Shared Value Recognition'. The survey was made on the employees of LH, which is a representative case of public corporation advancement, and SPSS 17.0 and AMOS 17 were used for the analysis. As a result of the analysis of a structural equation model, it indicated that both 'planned PMI activities' and 'voluntary integration efforts' have direct influence on 4 indices of effectiveness of an organization respectively. In particular, it was found that 'planned PMI activities' affects 'Shared Value Recognition' the most and 'voluntary integration efforts' has the largest effect on 'Emotional Integration'. Through this study, it was verified that voluntary integration efforts of members as well as the planed formal PMI activities are also very important factor of effect on the integration performance of an organization
\end{abstract}

Keywords: PMI, Organizational Effectiveness, Job Satisfaction, Organizational Commitment, Emotional Integration, Shared Values Recognition

\section{Introduction}

Looking at market trends of domestic M\&A (Merger \& Acquisition), total cases occurred during a single year of 2009 were 494 cases, which its scale considerably grew bigger enough to be around 21 trillion won (Ministry of Knowledge Economy, 2010). It can be seen that this expansion of the scale of M\&A market is caused by the increase of companies for sale according to the restructuring and liquidation of companies throughout industries in the process of going through financial crisis in 1997 and global financial crisis in 2008 (Hwang, M. S. and K. Kang, 2009). Although M\&A of companies is steadily being progressed for the purpose of reinforcement of a company's control over the market or strategic advance toward new business, it is the reality that the result of merger has many cases of failure contrary to expectations. In the survey by Bain \& Company on 250 persons from management in charge of M\&A of global companies, $60 \%$ of respondents answered that their efforts to raise the value of company by M\&A had failed (Kim, S. M., 2007). In case of the States, $57 \%$ among companies that were evaluated to be a successful combination in 2000 have gone through failure in the process of merger, and due to that, the performance was declined and several combined companies were also subdivided (Kim, $\mathrm{H}$. T., 2003).

Then, what should be importantly considered to make M\&A successful that is strategically selected for future growth or expansion of control over the market or ultimately expansion of a company's value? In domestic and foreign literature related with M\&A, they point out the deal making which means a success of M\&A contract itself and PMI (Post-Merger Integration) that is the integration activity after M\&A as key considerations (Kim, $\mathrm{H}$. T., 2003). However, according to a domestic study (Nam, D. I., 2001), while there is, in general, a high tendency of recognizing the deal making as the completion of integration process, it was found that the recognition of importance regarding PMI is low. Like this, the phenomenon that recognizes simple physical combination through deal making (signing a contract) as a concept of completion of integration is obvious, but as a result of survey on domestic 865 companies, it is largely pointed out that the issue of 'integration of organizational culture' along with

1) Research Fellow, Land \& Housing Institute (Main author: softmoon@lh.or.kr)

2) Research Fellow, Land \& Housing Institute (Corresponding author: pluto@lh.or.kr)

3) Senior Research Fellow, Land \& Housing Institute 
'manpower restructuring or leaving of experts' is impeding organizational performance after M\&A (Kim, 2008). Likewise, the result of A.T.Kearney's research, a global consulting company, demonstrates the importance of PMI after M\&A more and more. The survey conducted by A.T. Kearney on integration process (PMI) based on 115 cases of M\&A which was carried out from 1998 to 1999 showed that $53 \%$ of respondents pointed out PMI to be the most risky in the process of M\&A.

However, despite the importance of PMI, it's the reality that efforts and research regarding PMI from business and academic world are not sufficient. In the research of A.T. Kearney that was mentioned above, it was found that only $32 \%$ of responding companies established the definite guideline and formally managed the risk in the process of M\&A integration. In other words, even though more than $2 / 3$ companies spent huge sum of cost on M\&A, they did not exert special efforts in the management of risk (Park, 2005). Also in domestic academic world, there are mostly many themes with a financial view in the selection of the research subject related with M\&A and the studies on PMI are not sufficient (Kim, 2003). It is thought that this is because it takes long time for the performance of PMI to be visible, and it's not easy to evaluate the performance of PMI as well. Besides, since companies that failed in the merger are reluctant to leak data to the outside, it becomes a cause that a researcher has a limit (Go, 2009).

Meanwhile, in the integration of public sector, looking at progress pattern of government reorganization in the past, despite a great deal of efforts of organizational integration by former governments, the creation of synergy according to reorganization was not sufficient due to the lack of systematic integration management, and rather it has generated lots of side effects such as confusion of policy implementation etc. (Jo, and S. Hwang, 2008). Therefore, the systematic management of PMI must be considered to be an essential factor of success in organizational integration, and in particular, it is necessary to recognize 'management of personnel', 'management of culture' as the key management factors of integration to overcome diverse type of conflicts caused by the difference in heterogeneous organizational culture. In short, various methodologies and strategic approaches are required for how to systematically manage intangible factors other than physical integration in terms of M\&A, and systematic implementation and continuous efforts for PMI are required (Im, and Lee, 2008).

In this context, under the assumption that systematic PMI management is necessary for organizational integration to achieve properly effects of integration synergy that was initially expected, this study conducted the empirical analysis through the case of LH that was recently merged after argument for even 16 years. LH is the most representative integration case of public corporation and it was selected because it could give lots of implications to other institutions in the future. This paper is intended to reconfirm the importance of PMI activities through empirical analysis of various PMI activities that are still going on in LH, and to verify its effectiveness of PMI on emotional integration between members and company's shared value recognition and organizational effectiveness and finally to suggest implications.

\section{Theoretical Study}

\subsection{Concept and Definition of PMl (Post-Merger Integration)}

In general, the concept of 'integration' means that social system binds up many sub-factors that comprise of the system into one (Moorehead \& Griffin, 1992). A dictionary definition of integration is that 'more than two organizations or frameworks are rolled into one', and in terms of commercial law, it uses the term of amalgamation, which is recognized as 'a judicial act that more than two corporations are integrated into one corporation.'

The definition of PMI by Ministry of Public Administration and Security (2008) was that 'it's an activity to manage it systematically so that an organization integrated with other organizations having different working ways and organization cultures etc. can create the effect of synergy in a short period of time, and so that the expected conflicts in the sector of organizational culture, personnel matters, and function are overcome after reorganization of the government and employees can perform their jobs to achieve common goals of the integrated single department.' Im and Lee (2008) define PMI that 'after the merger of organizations, organizational culture such as management system, procedure, values and attitude through organic and chemical exchange of energy between two systems is completely and newly reformed through creative dissolution or managerial efforts to be reformed.' In this study, the definition of PMI will be "the overall activities to manage it systematically so that after more than two organizations are merged, members of the organization can achieve the common goals of the single organization effectively by overcoming emotional, psychological, and cultural sense of difference and conflicts and forming sense of unity."

\subsection{Measuring Index of Organizational Effectiveness of Merged Organization}

Organizational Effectiveness is a concept indicating that how well an organization is operated and is an evaluation of performance of an organization. The organizational effectiveness is a concept including the achievement of goals of an organization and personal goals (Shin, 1989). The studies on the organizational effectiveness don't present the unified picture due to researchers' many different theories and diversity of measuring standards and measuring methods.

The measurement of organizational effectiveness still has many issues of its concept, selecting criteria variables of measurement, its definition, and the level of analysis, but if the indexes of organizational effectiveness are generally divided into two, it can 
be divided into an objective index and a subjective index. Objective indexes include productivity, rate of return, sales, market share, turnover rate, absence rate etc. and there are many subjective indexes such as satisfaction, quality of working life, commitment, organizational atmosphere, adaptability etc. (Lee , 2010). Dalton et al. (1980) divided the measuring indexes of organizational effectiveness into two dimensions and thought that profitability, productivity, total sales fell under economical indexes and morale of members, job satisfaction, organizational commitment fell under psychological indexes. Campbell (1977) classified the indexes of organizational effectiveness into economical, psychological, and managerial indexes, and the economical indexes include productivity, efficiency, and profits and the psychological indexes include job satisfaction, motivation, morale, internalization of organizational goals etc. and the managerial indexes include the frequency of accidents, absence rates, turnover rate, and managers' administrative capabilities etc. These measuring criteria of organizational effectiveness focused on economical indexes at the early stage but recently show the tendency to understand it by including psychological or managerial indexes of members (Lee, 2010).

In this study, the indexes of emotional integration and shared value recognition are included into the indexes of job satisfaction and organizational commitment that are the most common ones for organizational effectiveness that are represented with attitude and behavior of members as psychological and subjective indexes to measure organizational effectiveness under the special situation of an integrated organization. According to preceding studies, psychological and subjective indexes affect economical and objective performance of an organization, and it is also considered that it's not easy to evaluate it through economical and objective performance at the early stage of integration.

\subsubsection{Job Satisfaction}

Alderfer (1972) defined job satisfaction that 'it's a set of attitudes that an individual has toward his/her job, and pleasant emotional state that is met by the result of a job or performance of a job', and Constance \& Becker (1993) defines job satisfaction that 'it's a state of pleasant and positive emotion that members can obtain in the evaluation of their jobs.' Locke (1976) defined job satisfaction that 'it's an pleasant or positive emotional state that can be obtained by personal job performance or the result of evaluation on job experience.' The studies on job satisfaction mainly had job satisfaction as a dependent variable making an effort to find out factors that affect job satisfaction of members and tried to predict the result variables of job satisfaction (job performance, productivity, turnover rate, and absence etc.). With these results of studies, the result variables of job satisfaction are somewhat proved but since there are so many preceding variables and the relationship between variables is considerably complicated, it is not yet definitely arranged (Lee and Jeong, 2002). In this study, job satisfaction is used as a dependent variable to conduct the verification of effectiveness on an independent variable (PMI).

\subsubsection{Organizational Commitment}

Meyer \& Allen (1991) conceptualized organizational commitment as 3 types of components such as affective commitment, continuance commitment and normative commitment. Affective commitment means that individual member feels sense of unity with emotional attachment to an organization. Continuance commitment, considering profit and loss occurred in case of leaving an organization, is the case to continue solidarity with an organization, and normative commitment is caused by internal values or faith that obligations as a member of an organization must be sincerely fulfilled. These three types of organizational commitment are based on different psychological states, and they come to have unity with an organization since affective commitment is based on 'want to', 'need to' for continuance commitment, and 'ought to' for normative commitment (Meyer, Allen \& Smith, 1993).

According to the result of research by Meyer \& Allen (1997), it was found that the most effective measuring index for organizational commitment was affective commitment. As a result of their research, it was found that while this did not act as an important motivating factor in case of a group with high continuance commitment or with high normative commitment, affective commitment had very high influence on performance of an organization.

Mowday, Porter \& Steers (1979) who established a base of a study on organization commitment suggested that organizational commitment represents being equal to an organization that a person belongs to, commitment, sense of unity, attachment and means strong trust on goals or values that the organization pursuits and mind to make an effort for an organization, and a will to stay a member. Therefore, commitment that they suggested also generally presuppose emotional and sensitive dimension (Cook, Hepworth, Wall \& Warr, 1981). Therefore, affective commitment was also used for the index of organizational commitment.

\subsubsection{Emotional Integration}

Emotional Integration means the state that sense of closeness among members increases and inconvenience or sense of difference disappear. The relief of inconvenience or sense of difference can be said to be very important achievement in terms of personal dimension before sense of difference caused by numerous institutional, cultural and job differences in an integrated organization after working for a different organization. Jeong (2000) inferred that the form of 'organizational integration' through the analysis of cases that made a success in organizational integration was the state that conflicts between subordinate departments disappear and members of the organization forgot where they belonged to after the merger. Emotional integration is highly involved with the competency of communication among members of the organization. 
Choi (2008) said that the competency of communication should be prepared as one of 6 competencies of PMI. He explains that the absence of communication increases anxiety or sense of crisis on changing jobs, which leads to impediment of job efficiency and causes distrust on integration management and integration process.

\subsubsection{Shared Values Recognition}

Shared value recognition means how much members recognize and sympathize with new mission, vision, and key values of the integrated organization. Shared values refer to very special principle or standard that leads members' behavior or thinking of an organization toward specific direction. And there are many cases that generally the shared values are recognized as a fundamental factor for the existence of an organization or a success. For example, common values or ideology, the purpose of existence of a company etc. are included. O'reilly \& Chatman (1996) said that shared values 'are what are worthwhile or the belief on the importance, in other words, principles or standards that a specific individual or group regards it as to be important', and that is to say, shared values could be defined as 'collection of values agreed with and shared by members of a specific group.' Therefore, shared values are an aggregate of the most basic and sustainable creeds comprising of corporate culture and specify consciousness and behavior of members and become standards of judgement for decision-making, and are tools that get the entire organization focused on one point toward a goal and play a role as a compass of management. Even in the results of many studies by the preceding researchers on components of corporate culture, the factor of shared values is commonly included and also corporate culture $7 \mathrm{~S}$ model by Peters \& Waterman suggests it as the most important and dominant component of corporate culture (Shin, 2006). Therefore, measuring how much members of the integrated organization recognize and sympathize the newly established vision, mission and key values etc. will act as an effective index that can identify whether cohesiveness of organizational culture exists after integration or not and can judge the degree of formation of new organizational culture of the integrated organization.

\section{Review of Preceding Studies}

Ahn, Kim, Im, Chae (2009) identified that PMI has a mediated effect between the change of organizational culture that members recognize and behavior of jobs in the empirical analysis of the relationship between the change of organizational culture and public servants' behavior of their jobs in Ministry of Land, Transport, and Maritime affairs. In the case that job satisfaction and organizational commitment are dependent variables, it showed that the bigger the difference of task culture between the present and the past was, the higher job satisfaction and organizational commitment were, and it was found that the higher the positive recognition on communication, mutual cooperation, and improving competency was, the higher job satisfaction and organizational commitment were on average.

Hwang, Cho, Choi, (2010) suggested that the sectors that represented positive results were function integration and personnel matters integration through frequency analysis as a result of looking through the sector of integration by dividing it into mission and vision integration, corporate culture integration, personnel integration, function integration and performance integration in the study on PMI and its effect of the integrated departments of the government. As a result of looking through organization satisfaction, organizational commitment, reduction of trading cost, liberalization of policy function and process etc, the effect of integration of departments generally identified positive results, and especially, it was verified that organizational commitment was high due to the nature of public servants. But, this study has a limit that the analysis of the relation of cause and effect on the relationship between PMI and its effect was not conducted.

Kim (2003) identified that cultural integration rather than physical and structural organizational integration had a positive $(+)$ effect on all of organizational commitment, job satisfaction, and disposition of changing jobs in the study on the effect of culture and organizational integration on the effectiveness of an organization after M\&A. Besides, the acquired company, in the case that it recognizes the level of corporate culture of the acquiring company as to be high, ascertained that the effectiveness of organization became higher. Kim (2007) verified that in-company communication had a meaningful influence on organizational commitment through the comparison of companies that progressed active in-company communication with other companies that did not in the study on the effect of in-company communication on organizational commitment of members in the process of PMI after M\&A.

Robino \& DeMeuse (1985) suggested that the satisfaction of employees of an acquired company was low in terms of job satisfaction, job stability, communication and participation, possibility of promotion and expansion of chance of growth etc. in the analysis of organizational effect between an acquiring company and an acquired company. Cray \& Mallory (1998) proved that rate of return became low after integration in the case that PMI was not made due to insufficiency of cultural appropriateness of both organizations when merged, and that the productivity was largely improved in the case that PMI was successfully made since its cultural appropriateness became high.

Looking through previous studies, it's the state that the study itself that verified the effectiveness of organizational integration is yet very insufficient, and it's the real fact that systematization for factors of an effect is insufficient as well. However, in the majority of preceding studies, the importance of emotional integration activities is verified over and over again. 


\section{Research Design}

\subsection{Research Model}

In this study, the planned PMI activity and efforts of voluntary integration of members were set up as independents variables. The planned PMI acitivity is related with various activities and programs that were conducted at the dimension of a company to be helpful for integration of members focusing on the department in charge of it. Besides, efforts of voluntary integration are the degree of efforts that members made themselves since the inauguration of the integrated organization. Organizational commitment, job satisfaction, emotional integration and shared values recognition were set up as dependent values. Organizational commitment and job satisfaction are traditional measurement variables of organizational effectiveness, and emotional integration and shared values recognition are added as variables to measure effectiveness of an organization under a special situation of the integrated organization. Therefore, cause-and-effect relationship between variables such as PMI activity, voluntary integration efforts and variables of organizational effectiveness becomes to be investigated through empirical data in this research model.

\subsection{Hypothesis Generation}

The following research hypotheses were generated to verify the validity of the research model established on the basis of theoretical review and the preceding studies etc. The relation between the variables of 'planned PMI activity' and organizational effectiveness (organizational commitment, job satisfaction) has been dealt in previous studies. So to confirm the results of the preceding studies, hypotheses 1 thru 4 are generated. Hypotheses 5 thru 8 are newly induced to verify the exploratory variable of 'voluntary integration efforts'. The dependent variables of 'emotional integration' and 'shared values recognition' are newly added in this paper as an important factor for the organizational integration, so they are also involved in hypotheses 1 thru 8 .

(Hypothesis 1) The planned PMI activity will have a positive effect on organizational commitment.

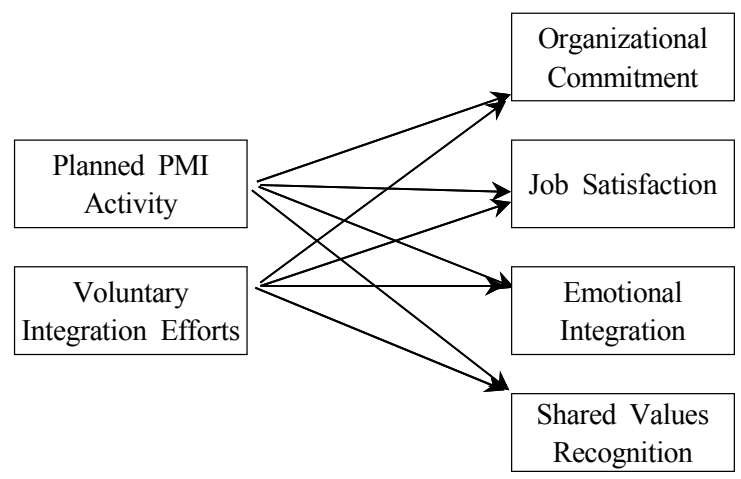

Fig. 1. Research Model
(Hypothesis 2) The planned PMI activity will have a positive effect on job satisfaction.

(Hypothesis 3) The planned PMI activity will have a positive effect on emotional integration.

(Hypothesis 4) The planned PMI activity will have a positive effect on shared values recognition.

(Hypothesis 5) The members' voluntary integration efforts will have a positive effect on organizational commitment.

(Hypothesis 6) The members' voluntary integration efforts will have a positive effect on job satisfaction.

(Hypothesis 7) The members' voluntary integration efforts will have a positive effect on emotional integration.

(Hypothesis 8) The members' voluntary integration efforts will have a positive effect on shared values recognition.

\subsection{Operational Definition of Variables}

\subsubsection{Independent Variables}

\section{(1) Planned PMI Activity}

PMI activities prepared and performed at the dimension of an organization include total 10 PMI activities such as CEO's integration leadership activities (CEO conversation court, CEO's message etc.), large-scaled outdoor events such as Harmony Hanmadang etc., optional type of integration activities with autonomy of department, cross-department activities such as putting themselves in others' shoes, GWP/new corporate culture campaign, participation of contribution activities for a society, operation of notice board for organizational integration/new corporate culture, online quiz contest regarding job introduction/ jobs, executives and staff members harmony training, and reflection of internal evaluation on integration activities etc. and the value of variables was measured by an individual recognition in respect to each activity.

\section{(2) Voluntary Integration Efforts}

The members' voluntary integration efforts that can be said to be informal nature measured interest and consideration for junior staffs of direct seniors and the second seniors under the situation that cross-displacement was made after the merger. In other words, regardless of one's native institution before integration, the degree of efforts for harmony and job interest and the degree of assistance for junior staffs by direct seniors and the second seniors were measured.

\subsubsection{Dependent Variables}

\section{(1) Organizational Commitment}

Organizational commitment was measured with 4 items such as the same feeling between a success of a company and a 
personal success, a sense of unity regarding destiny of a company and a person, seriousness in respect to the future of a company and sense of belonging to a company etc.

\section{(2) Job Satisfaction}

Job satisfaction was measured with 4 items such as job achievement, passion on jobs, sincerity of jobs, the degree of the best efforts for performance of jobs etc.

\section{(3) Emotional Integration}

Emotional integration was measured with 5 items such as sense of difference from staffs from other company, discomfort according to the mixed working, the degree of experiencing conflicts, and the degree of conflict resolution etc. since one year after the inauguration of integration.

\section{(4) Shared Values Recognition}

Shared values recognition was measured with 5 items such as the degree of recognizing mission and vision of a company, sympathy for the mission and vision, job connectivity of the mission and vision, key values recognition, and key values sympathy etc.

\section{Results of Empirical Analysis}

\subsection{Collection of Data}

The survey on staffs of LH company which is an integrated

Table 1. Features of Samples

\begin{tabular}{|c|c|c|c|}
\hline \multirow{2}{*}{ Classification } & \multirow{2}{*}{ Item } & \multicolumn{2}{|c|}{ Sample } \\
\hline & & Response & Ratio (\%) \\
\hline \multirow{3}{*}{$\begin{array}{l}\text { Working } \\
\text { Place }\end{array}$} & Main Office & 622 & 26.4 \\
\hline & $\begin{array}{l}\text { Regional Headquarters and } \\
\text { Project Agency Desk Job }\end{array}$ & 1,164 & 49.4 \\
\hline & Field & 571 & 24.2 \\
\hline \multirow{5}{*}{ Position } & Above Director & 16 & 0.7 \\
\hline & General Manager & 215 & 9.1 \\
\hline & Deputy General Mgr. & 726 & 30.8 \\
\hline & Manager & 1188 & 50.4 \\
\hline & Below Asst. Mgr. & 212 & 9.0 \\
\hline \multirow{4}{*}{$\begin{array}{l}\text { Working } \\
\text { Years }\end{array}$} & Less than 5 Years & 322 & 13.7 \\
\hline & 5 to less than 10 & 523 & 22.2 \\
\hline & 10 to less than 20 & 560 & 23.8 \\
\hline & more than 20 years & 952 & 40.4 \\
\hline \multirow{4}{*}{ Age } & Below 20's & 101 & 4.3 \\
\hline & 30 's & 818 & 34.7 \\
\hline & 40 's & 1,084 & 46.0 \\
\hline & Above 50's & 354 & 15.0 \\
\hline \multicolumn{2}{|r|}{ Total } & 2,357 & 100 \\
\hline
\end{tabular}

corporation was conducted to verify the research model and hypotheses that were set up through the preceding studies. For the method of investigation, in-company portal was utilized and there were 2,374 respondents, which is around $38 \%$ of total staffs. The samples necessary for structural equation were sufficiently gathered by utilizing 2,357 responses except for ones that were insufficient or insincere answered. Table 1 shows the features of samples that were collected for the empirical analysis in this study.

\subsection{Verification of Reliability and Validity of Variables}

Reliability was verified by a method utilizing internal conformity, in other words, by calculating Cronbach Alpha Coefficient. As a result of reliability analysis of the measured variables through SPSS, the value of Cronbach Alpha Coefficient is mostly over than 0.85, which represented to be satisfactory (See Table 2).

Exploratory factor analysis was conducted on the verified variables through reliability analysis for the verification of composition validity. The method used for exploratory factor analysis was principal components analysis, and rotation of factors was analyzed by varimax rotation having Kaiser normalization. It was judged to be meaningful in case that communality of each item that shows the degree of interrelation between each item and a factor exceeds 0.5 and factor loading exceeds 0.5 .

Validity was additionally analyzed through confirmatory factor analysis by AMOS 17. As a result of confirmatory factor analysis, standardized regression weights also represented to be satisfactory at the level $(p<0.01)$ that all the measured variables were meaningful in latent variable. Besides, as a result of calculating construct reliability2), only one variable was 0.898 and the others were more than 0.9 , which showed very high results. Generally, it is thought that when construct reliability is more than 0.7 , it can be acceptable (Hair et al, 1998). Recently, there is a tendency that the result of reliability analysis by Cronbach Alpha Coefficient is replaced with the result of construct reliability which is calculated by the analysis through a model of structural equation (See Table 3 ).

Besides, validity of prediction and distinction were looked into to identify the difference of composition concepts of each factor. First, it can be judged that since Average Variance Extracted of each factor is more than 0.5 and greater than multiple correlation coefficient $\left(\mathrm{r}^{2}\right)$, concepts were by and large measured well.

\subsection{Verification of Hypotheses}

\subsubsection{Model Fit}

A model of structural equation that analyzes cause-and-effect relationship between each conceptual construct was used to verify hypotheses of this study, and AMOS 17 program was used. First, the fit of the model was shown as follows and it generally represented to be satisfactory. 
Table 2. Results of Reliability and Validity through Exploratory Factor Analysis

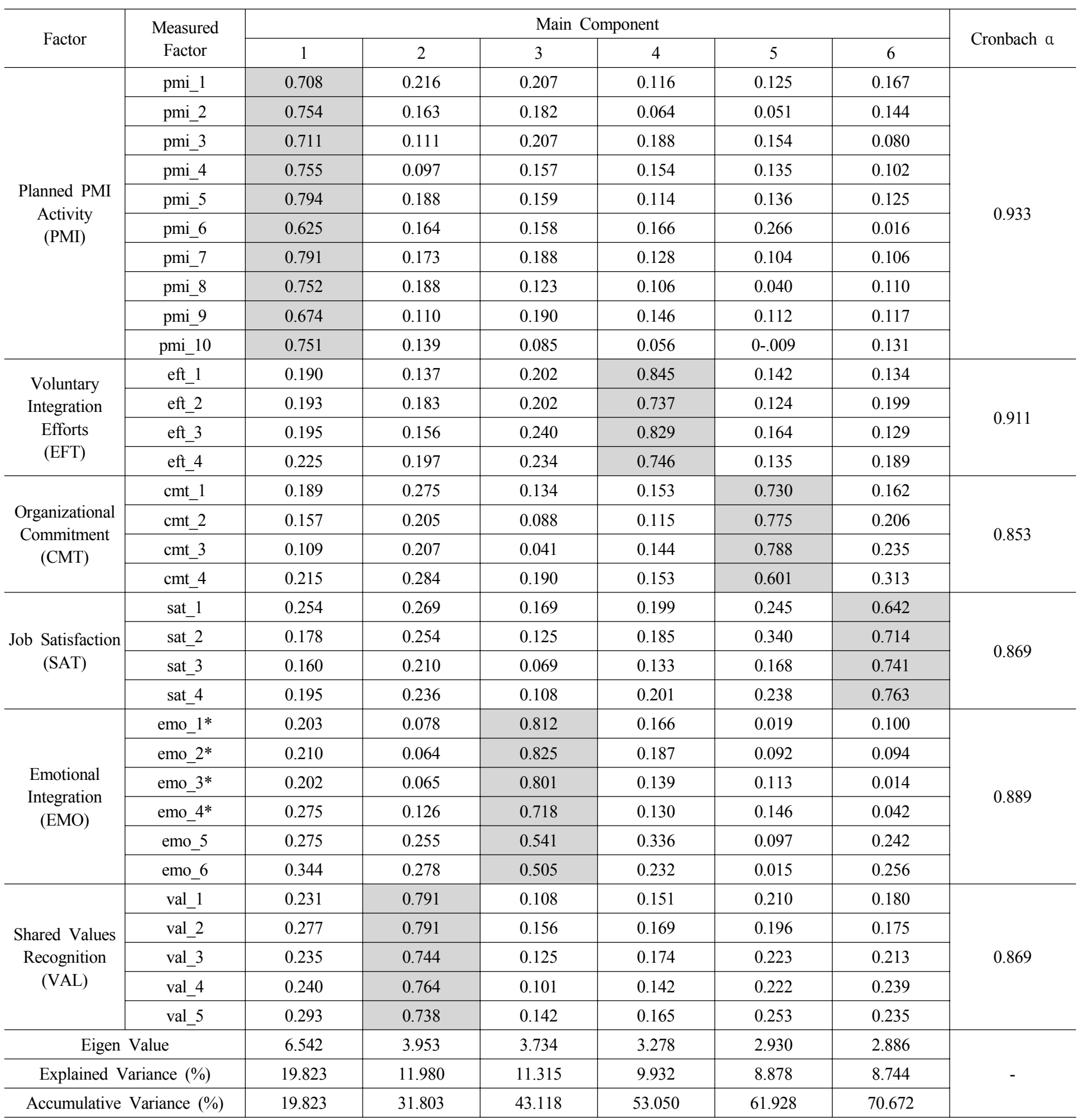

* Reverse Coding was conducted with negative questionnaire.

\subsubsection{Verification of Hypotheses}

As a result of statistical analysis, 8 hypotheses were all satisfactory and adopted. Therefore, it was found that there is cause-and-effect relationship between two independent variables and four dependent variables that were set up in this study. In other words, it can be known that both 'the planned PMI activity' and 'voluntary integration efforts' had a positive effect on organizational commitment, job satisfaction, emotional integration, and shared values recognition. Especially, it suggested that in the case of the planned PMI activity, it has the biggest effect on shared values recognition, and in the case of voluntary integration efforts, it has the biggest effect on emotional integration. 
Table 3. Results of Construct Reliability through Confirmatory Factor Analysis

\begin{tabular}{|c|c|c|c|}
\hline $\begin{array}{l}\text { Measured } \\
\text { Variable }\end{array}$ & $\begin{array}{c}\text { Standardized } \\
\text { Regression Weights }\end{array}$ & Standard Error & $\begin{array}{l}\text { Construct } \\
\text { Reliability }\end{array}$ \\
\hline pmi_1 & 0.767 & 0.410 & \multirow{10}{*}{0.940} \\
\hline pmi_2 & 0.753 & 0.492 & \\
\hline pmi_3 & 0.734 & 0.370 & \\
\hline pmi_4 & 0.754 & 0.380 & \\
\hline pmi_5 & 0.865 & 0.194 & \\
\hline pmi_6 & 0.695 & 0.386 & \\
\hline pmi_7 & 0.845 & 0.225 & \\
\hline pmi_8 & 0.763 & 0.332 & \\
\hline pmi_9 & 0.718 & 0.411 & \\
\hline pmi_10 & 0.716 & 0.518 & \\
\hline eft_1 & 0.896 & 0.127 & \multirow{4}{*}{0.949} \\
\hline eft_2 & 0.783 & 0.264 & \\
\hline eft_3 & 0.940 & 0.075 & \\
\hline eft_4 & 0.855 & 0.188 & \\
\hline cmt_1 & 0.782 & 0.172 & \multirow{4}{*}{0.930} \\
\hline $\mathrm{cmt} 2$ & 0.777 & 0.169 & \\
\hline cmt_3 & 0.788 & 0.127 & \\
\hline cmt_4 & 0.775 & 0.270 & \\
\hline sat_1 & 0.798 & 0.310 & \multirow{4}{*}{0.908} \\
\hline sat_2 & 0.872 & 0.128 & \\
\hline sat_3 & 0.663 & 0.351 & \\
\hline sat_4 & 0.812 & 0.212 & \\
\hline emo_1 & 0.765 & 0.374 & \multirow{6}{*}{0.898} \\
\hline emo_2 & 0.777 & 0.350 & \\
\hline emo_3 & 0.754 & 0.410 & \\
\hline emo_4 & 0.762 & 0.339 & \\
\hline emo_5 & 0.710 & 0.323 & \\
\hline emo_6 & 0.668 & 0.430 & \\
\hline val_1 & 0.849 & 0.177 & \multirow{5}{*}{0.955} \\
\hline val_2 & 0.877 & 0.151 & \\
\hline val_3 & 0.832 & 0.193 & \\
\hline val_4 & 0.848 & 0.190 & \\
\hline val_5 & 0.875 & 0.155 & \\
\hline
\end{tabular}

Table 4. Correlation Coefficient Between Factors and Average Variance Extracted 1 )

\begin{tabular}{c|c|c|c|c|c|c}
\hline Factors & 1 & 2 & 3 & 4 & 5 & 6 \\
\hline 1. PMI & 0.582 & & & & & \\
\hline 2. EFT & $0.497^{* *}$ & 0.758 & & & & \\
\hline 3. CMT & $0.501^{* *}$ & $0.509^{* *}$ & 0.548 & & & \\
\hline 4. SAT & $0.538^{* *}$ & $0.563^{* *}$ & $0.759^{* *}$ & 0.733 & & \\
\hline 5. EMO & $0.629^{* *}$ & $0.616^{* *}$ & $0.456^{* *}$ & $0.497^{* *}$ & 0.609 & \\
\hline 6. VAL & $0.604^{* *}$ & $0.526^{* *}$ & $0.701^{* *}$ & $0.709^{* *}$ & $0.497^{* *}$ & 0.624 \\
\hline
\end{tabular}

** significance at $\alpha=0.01$.
Table 5. Results of Fit on Confirmatory Factor Analysis and Research Model

\begin{tabular}{|c|c|c|c|c|}
\hline \multirow[b]{2}{*}{$\begin{array}{l}\text { Indices } \\
\text { of Fit }\end{array}$} & \multicolumn{2}{|c|}{ Fit } & \multirow[b]{2}{*}{ Criteria of Fit } & \multirow[b]{2}{*}{ Reference } \\
\hline & $\begin{array}{c}\text { Confirmatory } \\
\text { Factor } \\
\text { Analysis } \\
\end{array}$ & $\begin{array}{c}\text { Research } \\
\text { Model }\end{array}$ & & \\
\hline$x^{2}$ & 2253.002 & 4210.886 & \multirow{2}{*}{$\begin{array}{c}\text { samples }>200 \\
\text { improper for } \\
\text { evaluation } 2 \text { ) }\end{array}$} & \multirow{2}{*}{$\begin{array}{c}\text { Marsh et al. } \\
\text { (1988) }\end{array}$} \\
\hline $\mathrm{p}$ & 0.000 & 0.000 & & \\
\hline$\chi^{2} / \mathrm{df}$ & 4.877 & 8.959 & less than 5 & $\begin{array}{c}\text { Hayduck } \\
\text { (1987) }\end{array}$ \\
\hline GFI & 0.943 & 0.893 & more than 0.90 & Scott (1994) \\
\hline AGFI & 0.931 & 0.873 & more than 0.90 & Scott (1994) \\
\hline TLI & 0.965 & 0.928 & more than 0.90 & $\begin{array}{c}\text { Tucker \& } \\
\text { Lewis (1973) }\end{array}$ \\
\hline PNFI & 0.842 & 0.827 & more than 0.60 & $\begin{array}{c}\text { James et al. } \\
(1982)\end{array}$ \\
\hline NFI & 0.962 & 0.929 & more than 0.90 & $\begin{array}{c}\text { Bentler \& } \\
\text { Bonnet }(1980)\end{array}$ \\
\hline CFI & 0.969 & 0.936 & more than 0.90 & Bentler (1992) \\
\hline RMR & 0.036 & 0.050 & less than 0.05 & $\begin{array}{c}\text { Hu \& Bentler } \\
\text { (1995) }\end{array}$ \\
\hline RMSEA & 0.041 & 0.058 & less than 0.08 & $\begin{array}{c}\text { Browne \& } \\
\text { Cudeck (1993) }\end{array}$ \\
\hline
\end{tabular}

Table 6. Results of Hypotheses Verification

\begin{tabular}{c|c|c|c|c|c}
\hline \multicolumn{2}{c|}{ Hypothesis (Path) } & $\begin{array}{c}\text { Path } \\
\text { Coefficient }\end{array}$ & t-value & P & Decision \\
\hline H1 & PMI $\rightarrow$ CMT & 0.362 & 15.041 & $0.000^{* *}$ & Adopted \\
\hline H2 & PMI $\rightarrow$ SAT & 0.377 & 16.388 & $0.000^{* *}$ & Adopted \\
\hline H3 & PMI $\rightarrow$ EMO & 0.419 & 19.765 & $0.000^{* *}$ & Adopted \\
\hline H4 & PMI $\rightarrow$ VAL & 0.475 & 21.445 & $0.000^{* *}$ & Adopted \\
\hline H5 & EFT $\rightarrow$ CMT & 0.342 & 14.707 & $0.000^{* *}$ & Adopted \\
\hline H6 & EFT $\rightarrow$ SAT & 0.391 & 17.529 & $0.000^{* *}$ & Adopted \\
\hline H7 & EFT $\rightarrow$ EMO & 0.416 & 20.510 & $0.000^{* *}$ & Adopted \\
\hline H8 & EFT $\rightarrow$ VAL & 0.296 & 14.647 & $0.000^{* *}$ & Adopted \\
\hline$* *$ p $<0.01$ & & &
\end{tabular}

\section{Conclusion}

As a result of empirical analysis, it was found that both the planned PMI activity that can be said to be formal organizational integration activity under the situation of an organization that two organizations were integrated and members' voluntary integration efforts had a positive effect on the performance of organizational integration. In particular, it was verified that members' voluntary integration efforts was very important as much as the necessity of formal PMI activity in this study. To conclude, if the implications in this study are summarized, they are as follows.

First, it was reconfirmed that formal and planned PMI activity

1) For Average Variance Extracted, there are methods such as Hair et. al (2006) and Fornell \& Larker (1981) but the method of Hair 
at the dimension of a company resolves sense of difference and conflicts and has a positive effect on emotional integration. This means that it is surely necessary to make an effort for the continuous and systematic PMI management for cultural, emotional and chemical integration after physical integration called as M\&A. How long the effort for PMI management should be continued may vary depending on each organizational situation but it will be necessary to respond strategically by conducting regular diagnosis and evaluation during PMI activities.

Second, it is the fact that informal and voluntary integration efforts focusing on a head of a department or senior managers in an organization also have a great influence on organizational integration. This is a part that can be compared with the fact that the preceding studies mainly focused on formal integration activities at the dimension of a company in the meantime. It can be known that the role of leadership that naturally forms sense of closeness and mutual understanding and cooperative atmosphere in the situation that contacts regarding a job between members occur on a daily basis by senior managers is a very important factor in organizational integration.

Third, it is the fact that there is difference between formal PMI activity and voluntary integration efforts in terms of the effect on the effectiveness of an organization. In other words, it was verified that while formal PMI activity is very effective in reinforcing the sense of unity of an organization through recognition and sympathy in respect to shared values such as mission and vision, key values etc. of new integrated organization, voluntary integration efforts was more effective method to increase emotional sense of unity and sense of closeness between members of an organization. These results imply that it is also necessary to make an effort to induce formal integration activities to be developed for organization integration in the future. It is very important for these efforts to be made through taking the initiative by seniors with higher rank than middle managers.

Lastly, various personnel matters and organizational conflict factors to be solved still exist for organizational integration. It is hoped that this part will continuously be dealt with as a subject of subsequent studies. And since the research model of this study involves some exploratory variables such as 'voluntary integration efforts', 'shared value recognition', 'emotional integration', and the object of the study is just one corporation, the generalization of the empirical results remains as a limitation of this study.

\section{Reference}

1. Ahn, G. S., N. Kim and C. Im (2009), "The Empirical Analysis of

et. al (2006) that almost matches with values obtained through complete standardization at LISREL and shows strict numerical value was calculated and utilized for the analysis of validity.

2) In general, as the sample size increases, the value of $\chi^{2}$ becomes bigger. So if the sample size is bigger than 200 , this criterion is not useful.
Relationship Between Changes of Organizational Culture and Job Behavior of Public Servants in Ministry of Land, Transport and Maritime Affairs: Focusing on Mediated Effect on PMI", Collection of Dissertation of Korea Administration, 21(2): 651 679 .

2. Alderfer, C. (1972), Existence, Relatedness and Growth, New York, Free Press.

3. Bae, B. R. (2008), AMOS 17.0 Structural Equation Modeling: Principle and Reality (2nd Edition), Cheong Ram Publishing Group.

4. Bentler, P. M. and D. Bonett (1980), "Significance tests and goodness of fit in the analysis of covariance structures", Psychological Bulletin, 88: 588 606 .

5. Bentler, P. M. (1992), "On the fit of models covariances and methodology to the bulletin," Psychological Bulletin, 112: 400 404.

6. Browne, M. W., and R. Cudeck (1993), Alternative ways of assessing model fit, in Bollen, K. A. and J. S. Long (Eds.), Testing structural equation models, Newbury Park, CA: Sage, $133 \sim 162$.

7. Campbell, J. P. (1977), On the Nature of Organizational Effectiveness, Jossey-Bass, San Francisco.

8. Cho, S. Y. and S. Hwang (2008), "Evaluation and Futuristic Tasks of PMI programs of Korean Government", Presented Dissertation at Autumn Academic Conference of Korean Association of Public Administration.

9. Choi, C. H. (2008), "Self-Evaluated Model for Effectiveness of PMI", Presented Dissertation at Autumn Academic Conference of Korean Association of Public Administration.

10. Constance, N. A. and M. Becker (1993), "Job Satisfaction and Performance: An Empirical Test of Some Theoretical Propositions", Organizational Behavior and Human Performance, 9(2): 267 279.

11. Cook, J. D., S. Hepworth, T. Wall and P. Warr (1981), The Experience of work, Academic Press, New York, NY.

12. Cray, D. and G. Mallory (1998), Making sense of Managing Culture, ITP.

13. Dalton, T., Spendolini, Fielding and Porter (1980), "Organizational Structure and Performance: A Critical Review”, Academy of Management Review, 5(1): $49 \sim 64$.

14. Go, Ja. H. (2009), "Study on PMI as Performance Evaluation of Financial Integration: Focusing on recognition difference of personnel matters integrated management of Woori Bank", National Policy Research, 23(4): 115 140.

15. Hair, J. F. Jr., R. Anderson, R. Tantham and W. Black (1998), Multivariate Data Analysis, 5th ed., Prentice-Hall International.

16. Hayduk, Leslie A. (1987), Structural Equation Modeling with LISREL: Essentials and Advances, The Johns Hopkins University Press.

17. Hu, L. T. \& P. Bentler (1995), Evaluating Model Fit, in R. H. Hoyle (Eds), Structural Equation Modeling: Concepts, Issues and Applications, Thousand Oaks, CA: Sage, 76 99.

18. Hwang, Mun Seong, Gang, Gi Woo (2009), "The Status of M\&A in Korea and Its Political Implication", Korea Bank, Investigation Bureau. 
19. Hwang, H. S., T. Cho and S. Choi (2010), "The Study on PMI and Its Effect of Integrated Departments", Journal of Korea Governance Society, 17(2): 113 137.

20. Im, Y. J. and C. Lee (2008), "The Introductory Study on PMI of Governmental Organization”, Journal of Korea Policy Science Society, 12(4): $133 \sim 154$.

21. James, L. R., S. Mulaik and J. Brett (1982), Casual Analysis: Assumptions, Models, and Data, Beverly Hills: Sage.

22. Kim, H. T. (2003), "Study on the Effect of Cultural and Organizational Integration after M\&A on the Effectiveness of an Organization", Dissertation for Doctor Degree, Kukmin University.

23. Kim, S. J. (2008), "M\&A Effect of Domestic Companies”, Sangjang 2008. February's issue, Korea Listed Companies Association.

24. Kim, S. H. (2007), "Effect of In-Company Communication on Organizational Commitment of Members of a Company in the Integration Process (PMI) After M\&A”, Dissertation for Master Degree, Seogang University.

25. Lee, J. H. (2010), “The Analysis of Effect of Organizational Culture and Job Characteristics on the Effectiveness of an Organization: Focusing on North Gyungsang Provincial Police Agency", Korea Information Society, 22(1): 181 215.

26. Lee, Y. G. and S. Jeong (2002), "The Empirical Analysis on the Effect of Working Values of Public Servants on Job Satisfaction and Organizational Commitment", Collection of Administrative Treatises, 43(1): $71 \sim 99$.

27. Locke, E. A. (1976), The Nature and Causes of Job Satisfaction, Handbook of Industrial and Organizational Psychology, Chicago: Rand Mcnally.

28. Marsh, H. W., J. Balla and R. McDonald (1988), "Goodness- of-fit indexes in confirmatory factor analysis: the effect of sample size", Psychological Bulletin, 103(3): 391 410.

29. Meyer, J. P. \& N. Allen (1991), “A Three-Component Conceptualization of Organizational Commitment", Human Resource Management Review, 1(1): 61 89.

30. Meyer, J. P. and N. Allen \& C. A. Smith (1993), "Commitment to organizations and occupations: Extension and test of a Threecomponent conceptualization", Journal of Applied Psychology, 78: $538 \sim 551$.
31. Meyer, J. P., and N. Allen (1997), Commitment in the Workplace: Theory, research and application, Thousand Oaks, CA: Sage Publications.

32. Ministry of Knowledge Economy (2010), "Statistics of the Status of M\&A as of 2008”, Release Copy. Seoul.

33. Ministry of Knowledge Economy (2010), "Statistics of the Status of M\&A as of 2009", Release Copy. Seoul.

34. Ministry of Public Administration and Security (2008), Manual of PMI, Seoul.

35. Moorhead, G. \& R. Griffin (1992), Organization Behavior, Boston: Houghton Mifflin.

36. Mowday, R. T., L. Porter \& R. Steers (1979), "The Measurement of Organizational Commitment”, Journal of Vocational Behavior, 14(2): $224 \sim 247$.

37. Nam, D. I. (2001), "Post-Merger Integration: PMI", Weekly Economy, LG Economic Research Institute, No.627

38. O'Reilly, C. A., and J. Chatman (1996), "Culture as social control: Corporations, culture and commitment," in B. M. Staw and L. L. Cummings (eds.), Research in Organizational Behavior, 18: 157 200.

39. Park, C. G. (2005), "5 Methods to Prevent Post-Effect of M\&A", Weekly Economy, LG Economic Research Institute, No. 835.

40. Robino, K. and K. DeMeuse (1985), "Corporate Mergers and Acquisitions: Their impact on HRM", Personnel Administrator, 30(11): $33 \sim 44$.

41. Shin, Y. G. (1989), Theory of Organizational Behavior, Seoul: Dasan Publishing Group.

42. Scott, J. (1994), "The measurement of information systems effectiveness: evaluating a measuring instrument," Proceedings of the 15th International Conference on Information Systems, Vancouver, BC, $111 \sim 128$.

43. Shin, T. G. (2006), "The Effect of Development of Key Values of a Company on Performance of Management : Focusing on cases of GE, Toyota, Samsung", Dissertation for Doctor Degree, Gyunghee University.

44. Tucker, L. R. and C. Lewis (1973), “A reliability coefficient for maximum likelihood factor analysis", Psychometrika, 38: 1 10. 